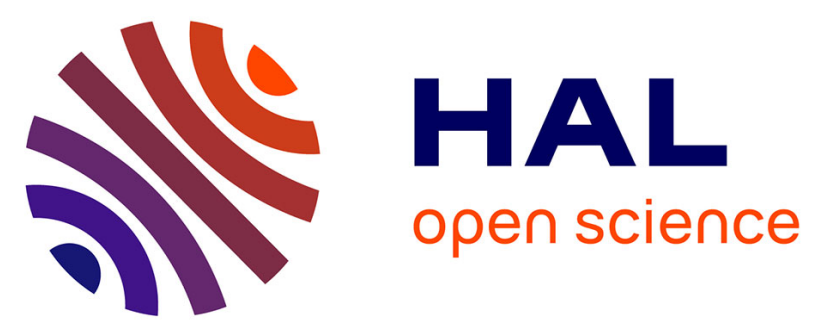

\title{
Influence of Thermal Treatment on Optical and Structure Properties of Europium-Doped SiO2-HfO2 Glasses
}

Chaofeng Zhu, Andre Monteil, Mohamed El Jouad, Nathalie Gaumer, Stéphane Chaussedent

\section{To cite this version:}

Chaofeng Zhu, Andre Monteil, Mohamed El Jouad, Nathalie Gaumer, Stéphane Chaussedent. Influence of Thermal Treatment on Optical and Structure Properties of Europium-Doped SiO2-HfO2 Glasses. Journal of the American Ceramic Society, 2010, 93 (4), pp.1039-1043. 10.1111/j.15512916.2009.03477.x . hal-03192915

\section{HAL Id: hal-03192915 \\ https://univ-angers.hal.science/hal-03192915}

Submitted on 8 Apr 2021

HAL is a multi-disciplinary open access archive for the deposit and dissemination of scientific research documents, whether they are published or not. The documents may come from teaching and research institutions in France or abroad, or from public or private research centers.
L'archive ouverte pluridisciplinaire HAL, est destinée au dépôt et à la diffusion de documents scientifiques de niveau recherche, publiés ou non, émanant des établissements d'enseignement et de recherche français ou étrangers, des laboratoires publics ou privés. 


\title{
Influence of Thermal Treatment on Optical and Structure Properties of Europium-Doped $\mathrm{SiO}_{2}-\mathrm{HfO}_{2}$ Glasses
}

\author{
Chaofeng Zhu, André Monteil, ${ }^{\dagger}$ Mohamed EI-Jouad, Nathalie Gaumer, and Stephane Chaussedent \\ Laboratoire des Propriétés Optiques des Matériaux et Applications (POMA), FRE CNRS 2988, Université d'Angers, \\ 49045 Angers Cedex 01, France
}

\begin{abstract}
$\mathrm{Eu}^{3+}$-doped $\mathrm{SiO}_{2}-\mathrm{HfO}_{2}$ glasses for optical applications were prepared using sol-gel technology. The effect of heat treatment on structure, emission properties and decay kinetics was investigated. The results show that the energy splitting of the ${ }^{7} \mathbf{F}_{2}$ state of $\mathrm{Eu}^{3+}$ ions occurs for the samples sintered at temperatures $>1000{ }^{\circ} \mathrm{C}$. This behavior can be explained by the fact that crystal phases are formed in those samples, which can be confirmed by X-ray diffraction analysis. Moreover, fluorescence line narrowing spectra for the samples sintered at different temperatures were measured, and the results were interpreted in terms of structural changes in the glass matrix and the $\mathrm{Eu}^{3+}$ bonding environment.
\end{abstract}

\section{Introduction}

TNORGANIC glasses doped with rare earth (RE) or transitional 1 metal ions are of great interest for fundamental studies and technical applications in optical devices such as laser materials, fiber amplifiers and waveguides, etc. ${ }^{1-4}$ The sol-gel process provides a potentially attractive technique for synthesizing these materials because of the wide range of compositions that is achievable and the ability to systematically study relationships among glass composition, structure, and optical properties of luminescent dopants. ${ }^{5,6}$ In addition, sol-gel technique allows the formation of the glass network at room temperature as a result of hydrolysis and condensation reactions of the precursors mixed in solution. The glass densification process can be realized by thermal treatment at much lower temperature than that of melting methods. ${ }^{7}$

In recent years, the study of integrated optical devices for telecommunication technology has attracted great research attention. ${ }^{8-10}$ In particular, much concern has been focused on RE ions-doped waveguides due to their low cost and reduced size. It was reported that the $\mathrm{SiO}_{2}-\mathrm{HfO}_{2}$ system is promising for successful applications in photonics. ${ }^{11,12}$ Moreover, the high refractive index and a good transparency in the visible range enable these kinds of materials to be used as valuable candidates for waveguides fabrication. Some reports are available regarding $\mathrm{Er}^{3+}$-doped $\mathrm{SiO}_{2}-\mathrm{HfO}_{2}$ materials. Sigoli et al. ${ }^{13}$ reported erbium and ytterbium co-doped $\mathrm{SiO}_{2}-\mathrm{HfO}_{2}$ glasses prepared by sol-gel method. They found the properties of this material can be modified by varying hafnia concentration in the silicate matrix. Jestin et al. investigated erbium activated $\mathrm{SiO}_{2}-\mathrm{HfO}_{2}$ glass ceramics waveguides. The role of hafnia on the structural, optical properties of this material was studied in their work. ${ }^{11}$

Some properties of $\mathrm{Eu}^{3+}$-doped $\mathrm{SiO}_{2}-\mathrm{HfO}_{2}$ glasses have been reported in our previous paper. ${ }^{8}$ Luminescence properties of materials can be modified by means of structure evolution which can be induced through thermal treatment. Since the optical proper-

J. Ballato-contributing editor

Manuscript No. 26521. Received July 20, 2009; approved September 30, 2009.

${ }^{\dagger}$ Author to whom correspondence should be addressed. e-mail: andre.monteil@univangers.fr ties of RE-doped materials depend intimately on the local structure and bonding of doped RE ions, a detailed understanding of these factors is important from a device engineering perspective. To the best of our knowledge, little effort has been made to investigate the effect of thermal treatment on the properties of $\mathrm{SiO}_{2}-\mathrm{HfO}_{2}$ glasses. In this paper, we will describe the properties of $\mathrm{Eu}^{3+}$-doped $\mathrm{SiO}_{2}-\mathrm{HfO}_{2}$ materials produced by sol-gel method and focus on the influence of the sintering temperature on the structure transition and its consequences on the photoluminescence and decay kinetics. Changes in spectroscopic properties with sintering temperature were observed. Besides, fluorescence line narrowing (FLN) spectra were also investigated. The observed changes of the FLN spectra as a function of the excitation wavelength are discussed in terms of the local environment of the $\mathrm{Eu}^{3+}$ ions, using elementary crystal-field theory.

\section{Experimental Procedure}

\section{(1) Materials}

Tetramethyl orthosilicate (TMOS, purity $>99.0 \%$ ) was purchased from Sigma-Aldrich (St. Louis, MO). Methanol $(\mathrm{MeOH}$, analytical reagent grade) was obtained from Fisher Scientific (Illkirch, France). Nitric acid $\left(\mathrm{HNO}_{3}\right.$, ca. $65 \%$ solution in water) and europium (III) nitrate hexahydrate (Eu $\left(\mathrm{NO}_{3}\right)_{3} \cdot 6 \mathrm{H}_{2} \mathrm{O}$, purity $>99.90 \%$ ) were purchased from Acros Organics. Hafnium (IV) dichloride oxide octahydrate $\left(\mathrm{HfOCl}_{2} \cdot 8 \mathrm{H}_{2} \mathrm{O}\right.$, purity $\left.>98 \%\right)$ was purchased from Strem Chemicals (Newburyport, MA). All the chemicals were used as received.

\section{(2) Synthesis of $\mathrm{Eu}^{3+}$-Doped $\mathrm{SiO}_{2}-\mathrm{HfO}_{2}$ Glasses}

In the present work, $90 \mathrm{SiO}_{2}-10 \mathrm{HfO}_{2}: 0.3 \mathrm{Eu}^{3+}$ (molar compositions) glasses were synthesized by using sol-gel route. The starting solution obtained by mixing TMOS, $\mathrm{MeOH}$, and deionized water, in the presence of $\mathrm{HNO}_{3}$ as a catalyst to promote the hydrolysis and condensation reactions, was prehydrolyzed for half an hour at room temperature to maximize the number of $\mathrm{SiOH}$ groups before mixing with the more reactive $\mathrm{HfOCl}_{2} \cdot 8 \mathrm{H}_{2} \mathrm{O}$ and to promote homogeneity within the mixed oxide samples. The chosen pre-hydrolysis conditions were TMOS:MeOH: $\mathrm{H}_{2} \mathrm{O}: \mathrm{HNO}_{3}$ in a 1:6:10:0.6 molar ratio, stirring for $0.5 \mathrm{~h}$. The appropriate quantity of $\mathrm{HfOCl}_{2} \cdot 8 \mathrm{H}_{2} \mathrm{O}$ was then slowly added to the prehydrolyzed TMOS solution while stirring. Europium was then introduced using $\mathrm{Eu}\left(\mathrm{NO}_{3}\right)_{3} \cdot 6 \mathrm{H}_{2} \mathrm{O}$ in the solutions mentioned above and the final mixture was let to react under stirring for $2 \mathrm{~h}$ at room temperature. Then the solutions were transferred into plastic beakers. The closed beakers were kept at $60^{\circ} \mathrm{C}$ for 5 days and heated to $80^{\circ} \mathrm{C}$ for 1 day. ${ }^{14,15}$ Gelation and aging of the samples took place within this period. The covers were then unscrewed to allow vaporization of residual solvents, and the samples were dried for 5 weeks at room temperature. Next, the dried samples were cut into several pieces and transferred into an electrical furnace and sintered in air using a heating rate of $1{ }^{\circ} \mathrm{C} / \mathrm{min}$ up to different final temperature. The samples were kept for $4 \mathrm{~h}$ at these temperatures and finally 
cooled to room temperature. The obtained samples have the approximate shape of a cuboid with the dimension of $\sim 4 \mathrm{~mm} \times 4 \mathrm{~mm} \times 5 \mathrm{~mm}$.

\section{(3) Characterizations}

The photoluminescence spectra was measured by using the 355 $\mathrm{nm}$ ultraviolet light from Nd-YAG laser. Fluorescence was focused on the entrance slit of a Jobin-Yvon THR 1500 spectrometer (Les Ulis, France) and detected by a cooled R943-02 Hamamatsu photomultiplier tube (PMT, Hamamatsu City, Japan). The PMT was connected to photon-counting electronics. The decay process of luminescence was recorded with a multichannel analyzer Stanford Research SR 430 via a fast amplifier discriminator (Stanford SR 445, Sunnyvale, CA). FLN spectra were measured at $77 \mathrm{~K}$ under excitation with a wavelength within the ${ }^{7} \mathrm{~F}_{0} \rightarrow{ }^{5} \mathrm{D}_{0}$ transition of $\mathrm{Eu}^{3+}$ ions using $532 \mathrm{~nm}$ line of Nd:YAG laser pumped Rhodamine $6 \mathrm{G}$ dye laser setup(Quanta Ray). Low temperature measurement conditions were obtained by placing the samples in a liquid nitrogen closed-cycle cryostat (Optistat DN-V cryostat, Oxfordshire, U.K.). Crystalline structures were evaluated by X-ray diffraction (XRD), using Bruker D8 Advance X-ray diffractometer (Karlsruhe, Germany) with $\mathrm{Cu} K \alpha$ radiation $(\lambda=0.1540 \mathrm{~nm})$.

\section{Results and Discussion}

Figure 1 displays the room temperature luminescence spectra of samples sintered at different temperatures, under $355 \mathrm{~nm}$ excitation. All spectra were normalized to the peak intensity of ${ }^{5} \mathrm{D}_{0} \rightarrow{ }^{7} \mathrm{~F}_{2}$ transition of $\mathrm{Eu}^{3+}$ around $612 \mathrm{~nm}$ for comparison. The spectra are essentially constituted by a group of emission lines ranging from 570 to $720 \mathrm{~nm}$, which are associated with the transitions from the excited state ${ }^{5} \mathrm{D}_{0}$ to the ground levels ${ }^{7} \mathrm{~F}_{\mathrm{j}}$ $(j=0-4)$ of $\mathrm{Eu}^{3+}$ ions. The emission lines observed between 580 and $605 \mathrm{~nm}$ and between 635 and $660 \mathrm{~nm}$ are assigned to the magnetic dipole transition, ${ }^{5} \mathrm{D}_{0} \rightarrow{ }^{7} \mathrm{~F}_{1}$ and ${ }^{5} \mathrm{D}_{0} \rightarrow{ }^{7} \mathrm{~F}_{3}$, respectively. ${ }^{16,17}$ On the other hand, the emissions in the region of $605-635 \mathrm{~nm}$, and centered at around $705 \mathrm{~nm}$ are attributed to the electronic dipole transitions, ${ }^{5} \mathrm{D}_{0} \rightarrow{ }^{7} \mathrm{~F}_{2}$ and ${ }^{5} \mathrm{D}_{0} \rightarrow{ }^{7} \mathrm{~F}_{4}$, respectively. ${ }^{16,17}$ In Fig. 1, there is one significant point worthy of discussion. Although the major peak positions in the emission spectra are all nearly identical, the emission behaviors are quite different. In the spectrum of samples sintered at $700^{\circ}$ and $900^{\circ} \mathrm{C}$, the emission related to the ${ }^{5} \mathrm{D}_{0} \rightarrow{ }^{7} \mathrm{~F}_{2}$ transition exhibits only one peak. While for the samples sintered at $1000^{\circ}$ and $1100^{\circ} \mathrm{C}$, the emissions due to the same electronic transition split into two peaks at 610 and $626 \mathrm{~nm}$, which suggests that the environment

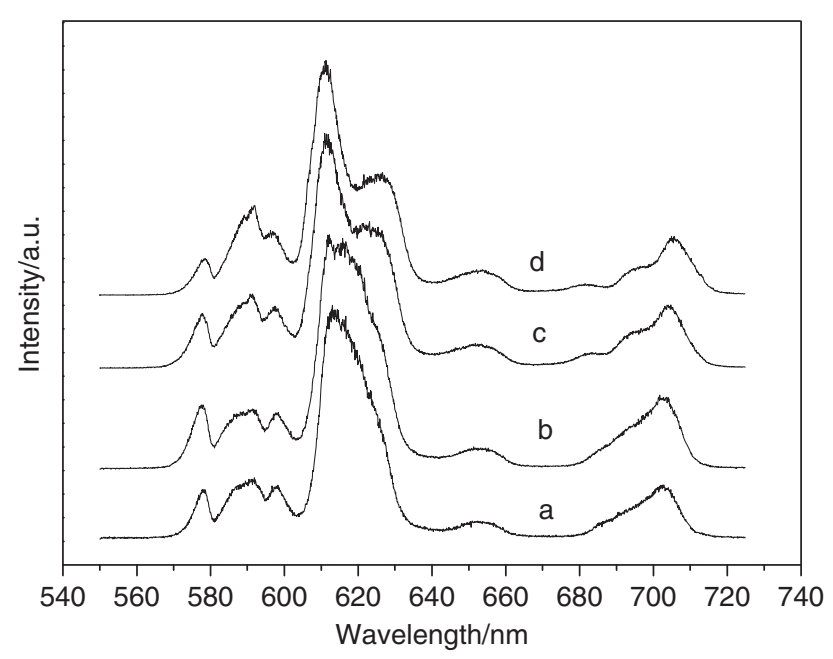

Fig. 1. Luminescence spectra of $90 \mathrm{SiO}_{2}-10 \mathrm{HfO}_{2}: 0.3 \mathrm{Eu}^{3+}$ glasses sintered at different temperature. (a) $700^{\circ} \mathrm{C}$; (b) $900^{\circ} \mathrm{C}$; (c) $1000^{\circ} \mathrm{C}$; (d) $1100^{\circ} \mathrm{C}$ around $\mathrm{Eu}^{3+}$ ions in low-temperature sintered samples is quite different from that in samples sintered at higher temperature. Since the ${ }^{5} \mathrm{D}_{0}$ state can not be split, ${ }^{18}$ the number of emission peaks corresponding to the ${ }^{5} \mathrm{D}_{0} \rightarrow{ }^{7} \mathrm{~F}_{2}$ transition is dependent on the energy level splitting of the ${ }^{7} \mathrm{~F}_{2}$ state. The presence of two emission peaks for the ${ }^{5} \mathrm{D}_{0} \rightarrow{ }^{7} \mathrm{~F}_{2}$ transition in the samples sintered at $1000^{\circ}$ and $1100^{\circ} \mathrm{C}$ indicates that the ${ }^{7} \mathrm{~F}_{2}$ state is separated into two different energy levels.

The sintering temperature dependence of the structure of the samples is investigated by using XRD, as shown in Fig. 2. XRD patterns show that the samples remain amorphous up to heat treatment at $900^{\circ} \mathrm{C}$. Along with the enhancement of heat treatment, it is obvious that the crystallization process starts after heat treatment at $1000^{\circ} \mathrm{C}$. The diffraction peaks could be indexed to tetragonal $\mathrm{HfO}_{2}$ crystal phase according to the research result reported by Afify et al. ${ }^{19}$ The average crystallite size (D) of crystalline $\mathrm{HfO}_{2}$ can be determined using the Scherrer formula: $D=k \lambda / \beta \cos \theta$, where $\lambda$ is the $X$-ray wavelength $(\lambda=0.1540 \mathrm{~nm})$ and the value of $k$ is $0.89, \beta$ (in radians) is the full-width at half-maximum (FWHM) of diffraction peak, and $\theta$ is the peak position. The average crystallites size of $\mathrm{HfO}_{2}$ in the samples sintered at $1000^{\circ}$ and $1100^{\circ} \mathrm{C}$ are 2.3 and $3.9 \mathrm{~nm}$, respectively. This result allows to correlate the sintering temperature with the crystallites size.

Some previous studies show that the electric dipole transition ${ }^{5} \mathrm{D}_{0} \rightarrow{ }^{7} \mathrm{~F}_{2}$ is a hypersensitive transition, ${ }^{20}$ which is sensitive to the chemical bonds formed between $\mathrm{Eu}^{3+}$ and its surrounding ligands. ${ }^{21}$ The luminescence properties of the samples are closely related to the local environment of the $\mathrm{Eu}^{3+}$ site, such as symmetry and $\mathrm{Eu}-\mathrm{O}$ distance. In the present work, the results of XRD analysis indicate that crystal phases are present in the samples sintered at $1000^{\circ}$ and $1100^{\circ} \mathrm{C}$. Herein, we think the creation of crystals can induce a shortening of the $\mathrm{Eu}-\mathrm{O}$ distance. Indeed, previous experimental studies have reported a shorter $\mathrm{Er}$ $\mathrm{O}$ distance in $\mathrm{Er}_{2} \mathrm{O}_{3}$ crystal than in Er-doped silica matrix. ${ }^{22,23}$ The overlap between $\mathrm{Eu}^{3+}$ and $\mathrm{O}^{2-}$ orbits with a short $\mathrm{Eu}-\mathrm{O}$ distance leads to a strong crystal field in the surrounding of $\mathrm{Eu}^{3+}$. On the other hand, energy splitting of the Stark components of the ${ }^{7} \mathrm{~F}_{2}$ state is caused by the strong crystal field. As a result, energy level splitting at the ${ }^{5} \mathrm{D}_{0} \rightarrow{ }^{7} \mathrm{~F}_{2}$ transition of the $\mathrm{Eu}^{3+}$ ions of the samples sintered at higher temperature occurred, resulting in two emission peaks. Hence, the formation of crystals is the factor responsible for the splitting of the ${ }^{5} \mathrm{D}_{0} \rightarrow{ }^{7} \mathrm{~F}_{2}$ emission band.

In an attempt to shed additional light on the influence of sintering temperature on the properties of glasses, measurements were made of the fluorescence decay for samples sintered at different temperature, as shown in Fig. 3. The decay profiles were performed with an excitation wavelength of $355 \mathrm{~nm}$ while mon-

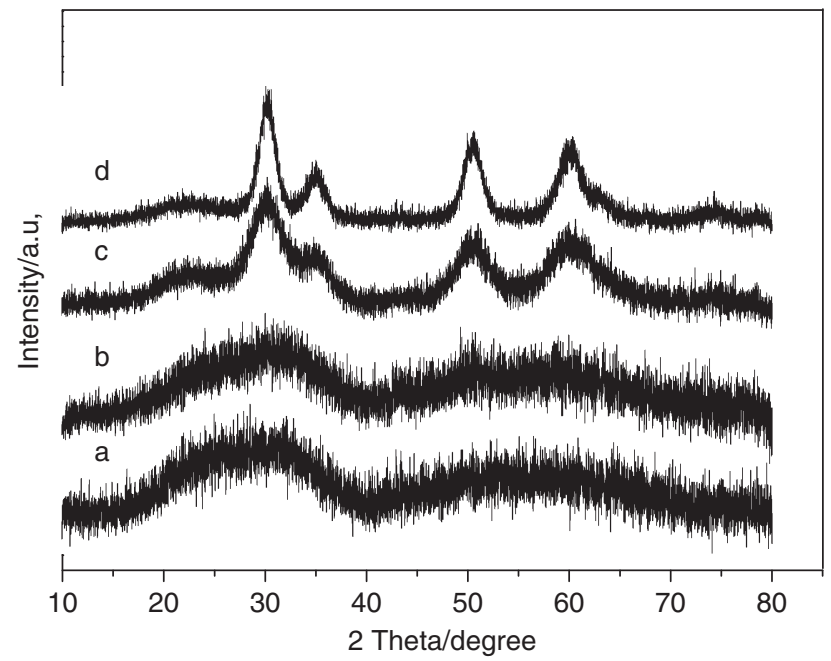

Fig. 2. X-ray diffraction patterns of $90 \mathrm{SiO}_{2}-10 \mathrm{HfO}_{2}: 0.3 \mathrm{Eu}^{3+}$ glasses sintered at different temperature. (a) $700^{\circ} \mathrm{C}$; (b) $900^{\circ} \mathrm{C}$; (c) $1000^{\circ} \mathrm{C}$; (d) $1100^{\circ} \mathrm{C}$ 


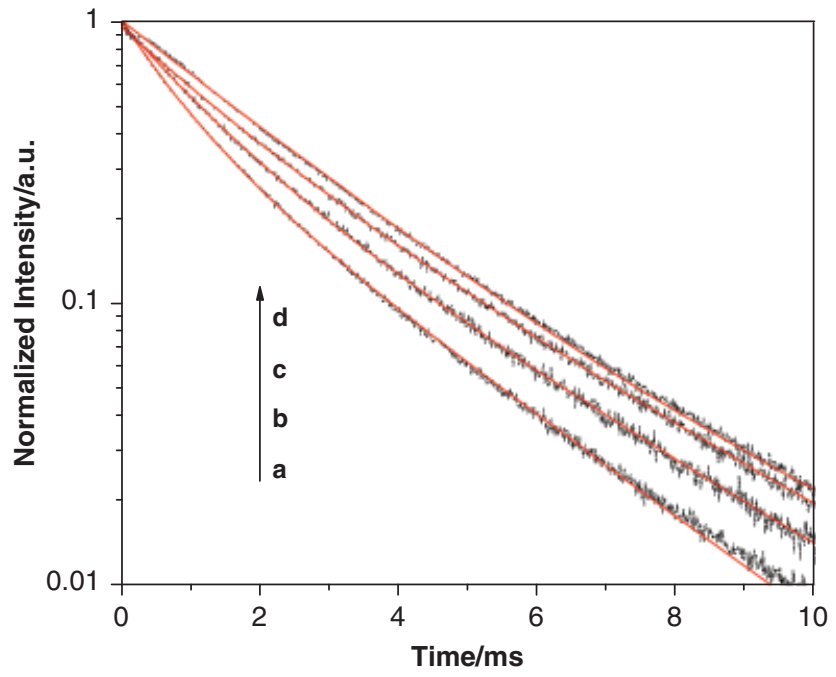

Fig. 3. Decay curves of $90 \mathrm{SiO}_{2}-10 \mathrm{HfO}_{2}: 0.3 \mathrm{Eu}^{3+}$ glasses sintered at different temperature. Black dotted line, experimental data; red solid line, fitting result by $I(t)=I_{1} \exp \left(-t / \tau_{1}\right)+I_{2} \exp \left(-t / \tau_{2}\right)$. (a) $700^{\circ} \mathrm{C}$ $\langle\tau\rangle=1.97 \mathrm{~ms}$; (b) $900^{\circ} \mathrm{C}\langle\tau\rangle=2.26 \mathrm{~ms}$; (c) $1000^{\circ} \mathrm{C}\langle\tau\rangle=2.50 \mathrm{~ms}$; (d) $1100^{\circ} \mathrm{C}\langle\tau\rangle=2.65 \mathrm{~ms}$.

itoring emission at the most intense peak of the ${ }^{5} \mathrm{D}_{0} \rightarrow{ }^{7} \mathrm{~F}_{2}$ band. The decay curves exhibited a not complete single-exponential profile for all the samples. For this reason, the lifetimes have been obtained by fitting the experimental decay data with a double-exponential curve of the form: $I(t)=I_{1} \exp \left(-t / \tau_{1}\right)+I_{2} \exp$ $\left(-t / \tau_{2}\right)$, where $I(t)$ is the luminescence intensity at the time $t$, $\tau_{1}$, and $\tau_{2}$ are lifetimes corresponding to the two components of the decay. The lifetimes have been calculated in evaluating an average value of the form $\langle\tau\rangle=\left(I_{1} \tau_{1}^{2}+I_{2} \tau_{2}^{2}\right) /\left(I_{1} \tau_{1}+I_{2} \tau_{2}\right)$, and were found to be $1.97,2.26,2.50$, and $2.65 \mathrm{~ms}$ for the samples sintered at $700^{\circ}, 900^{\circ}, 1000^{\circ}$, and $1100^{\circ} \mathrm{C}$, respectively. Thermal treatment process significantly affects the luminescent decays, i.e. lifetime increases with the increase of the sintering temperature.

The samples investigated in this paper were prepared by a sol-gel technique, therefore, in the gelation process, dry gels formed through hydrolysis and condensation always entrap some water, methanol, and other organic groups. An important effect of an aqueous environment is the quenching of luminescence of $\mathrm{Eu}^{3+}$ ions. ${ }^{15}$ In general, the organic residuals have high vibration frequencies and can efficiently quench luminescence of optically active ions. It is reported that the $\mathrm{OH}$ vibration frequency can be as high as $3340 \mathrm{~cm}^{-1}$, ${ }^{24}$ so that only five phonons are needed to bridge the excited state ${ }^{5} \mathrm{D}_{0}$ and the ground state ${ }^{7} \mathrm{~F}_{\mathrm{j}}$ levels of $\mathrm{Eu}^{3+}$. As a result, the presence of $\mathrm{OH}$ group near $\mathrm{Eu}^{3+}$ ions provides a nonradiative relaxation pathway and causes fluorescence quenching. On the other hand, thermal treatment can reduce or eliminate residual hydroxyl and other organic groups in the samples, reducing $\mathrm{OH}$ vibration quenching, and consequently increase the decay time. So, the lifetime increase with increasing sintering temperature is due to the reduction of the quenching centers.

FLN spectra are a good tool to examine the local structure around $\mathrm{Eu}^{3+}$ ions in glasses because each subset of $\mathrm{Eu}^{3+}$ ions can be selectively excited. ${ }^{25}$ FLN spectra obtained by selective excitation at different energies inside the ${ }^{7} \mathrm{~F}_{0} \rightarrow{ }^{5} \mathrm{D}_{0}$ transition between 570 and $580 \mathrm{~nm}$ for samples sintered at $700^{\circ}$ and $1100^{\circ} \mathrm{C}$ are shown in Fig. 4. Variations in the positions and shapes of the emission band under different excitation energy are clearly observed. The ${ }^{5} \mathrm{D}_{0} \rightarrow{ }^{7} \mathrm{~F}_{1}$ transition is obviously structured due to the Stark splitting of the ${ }^{7} \mathrm{~F}_{1}$ state, suggesting that the $\mathrm{Eu}^{3+}$ ions are located in sites with symmetry of $\mathrm{C}_{2 \mathrm{v}}$ or lower. It is apparent for the two samples that the shape and the peak position of components of the ${ }^{7} \mathrm{~F}_{1}$ level are dependent on the excitation energy. When the excitation wavelength is longer than about $576 \mathrm{~nm}$, the ${ }^{5} \mathrm{D}_{0} \rightarrow{ }^{7} \mathrm{~F}_{1}$ transition band in the FLN spectrum was clearly split into three peaks, while, the lower resolu-
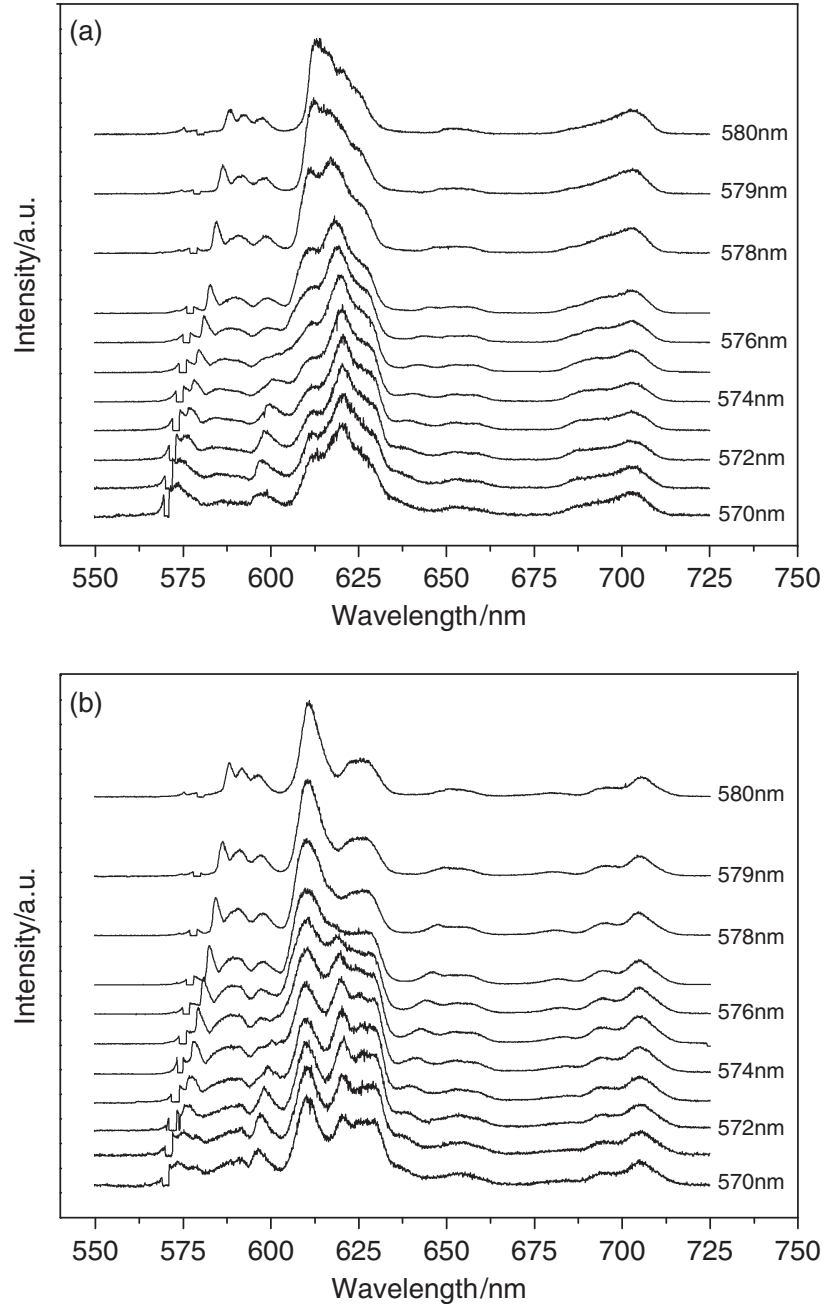

Fig. 4. Fluorescence line narrowing spectra obtained by selective excitation at different wavelengths between 570 and $580 \mathrm{~nm}$ with a $1 \mathrm{~nm}$ step for samples sintered at $700^{\circ} \mathrm{C}$ (a) and $1100^{\circ} \mathrm{C}$ (b), respectively. The spectra are normalized to the largest peak intensity and excitation wavelength is explicitly indicated in the figure.

tion of the Stark components of ${ }^{7} \mathrm{~F}_{1}$ level for high excitation energies is assigned to phonon sideband absorption. Although the emission from the ${ }^{5} \mathrm{D}_{0}$ level to the ${ }^{7} \mathrm{~F}_{1}$ state is split into three components, the behavior of these components is obviously different. The shortest wavelength component of the ${ }^{5} \mathrm{D}_{0} \rightarrow{ }^{7} \mathrm{~F}_{1}$ transition is considerably narrower than the other two and its position more sensitive to the excitation wavelength. Among the three emission lines of the ${ }^{5} D_{0} \rightarrow{ }^{7} F_{1}$ band, the highest-energy line shifted to the higher-energy side with increasing the excitation energy, while the two low-energy lines became broader and shifted separately into the opposite side. Since the ${ }^{7} \mathrm{~F}_{0} \rightarrow{ }^{5} \mathrm{D}_{0}$ excitation energy is a measure of the strength of the crystal field acting on central $\mathrm{Eu}^{3+}$ ions, such phenomenon displayed in FLN spectra can be attributed to the variation of the local crystal field strength around $\mathrm{Eu}^{3+}$ ions. Furthermore, the splitting of the ${ }^{7} \mathrm{~F}_{1}$ Stark levels increases with the excitation energy, suggesting the existence of a correlation between the crystal field strength and the excitation energy. With respect to the ${ }^{7} \mathrm{~F}_{2}$ state for the two samples, the intensity at about $612 \mathrm{~nm}$ peak decreased with increasing the excitation energy, whereas the peak intensity of 620 $\mathrm{nm}$ was enhanced. This behavior can be interpreted as the coexistence of two kinds of $\mathrm{Eu}^{3+}$ sites in the present glasses: one highly influenced by the presence of hafnium, and the other one unperturbed, as reported in our previous paper. ${ }^{8}$

FLN analysis provides a method to investigate variations in the local bonding environment of $\mathrm{Eu}^{3+}$ ions in inorganic glasses. A detailed local structure of two sites around $\mathrm{Eu}^{3+}$ ions can be 


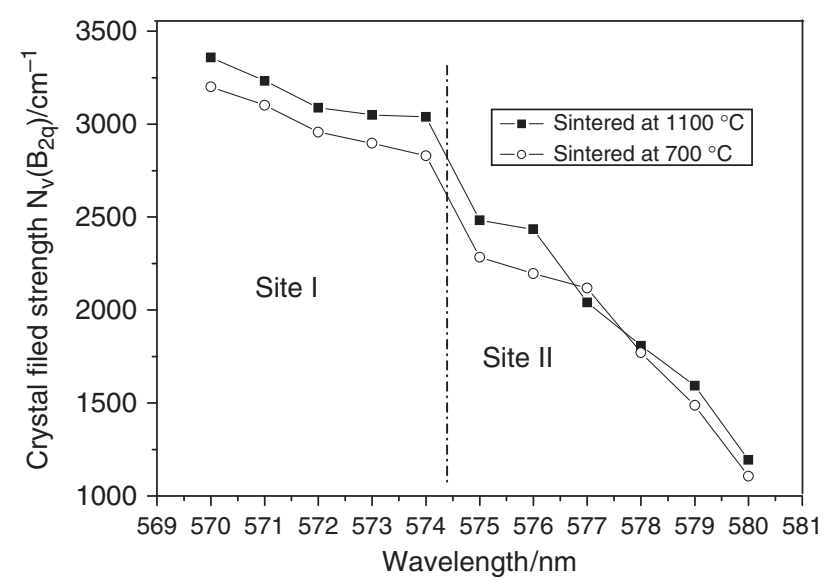

Fig. 5. Crystal field parameters $N_{v}\left(B_{2 q}\right)$ as a function of the excitation wavelength. The lines are a guide for the eye.

discussed from the viewpoint of crystal field theory. The secondorder crystal field parameters, $\mathrm{B}_{20}, \mathrm{~B}_{22}$, and crystal field strength $N_{v}\left(B_{2 q}\right)$ can be calculated from the ${ }^{7} \mathrm{~F}_{1}$ multiplet using the equations as the following 8 :

$$
\begin{aligned}
& E_{1}=E_{\mathrm{b}}+B_{20} / 5 \quad E_{2}=E_{\mathrm{b}}-\left(B_{20}-\sqrt{6} B_{22}\right) / 10 \\
& E_{3}=E_{\mathrm{b}}-\left(B_{20}+\sqrt{6} B_{22}\right) / 10 \\
& N_{v}\left(B_{2 q}\right)=\sqrt{4 \pi\left(B_{20}^{2}+2 B_{22}^{2}\right) / 5}
\end{aligned}
$$

where $E_{\mathrm{b}}$ denotes the barycentre of the ${ }^{5} \mathrm{D}_{0} \rightarrow{ }^{7} \mathrm{~F}_{1}$ multiplet and $E_{1}, E_{2}, E_{3}$ are the energies of the three Stark components of the ${ }^{5} \mathrm{D}_{0} \rightarrow{ }^{7} \mathrm{~F}_{1}$ transition. The wave numbers of the Stark levels belonging to ${ }^{7} F_{1}$ were obtained from the FLN spectra using a Gaussian deconvolution routine, details can be found in our previous paper. ${ }^{8}$ The crystal field strength $N_{v}\left(B_{2 q}\right)$ are plotted in Fig. 5 for the glass samples sintered at $700^{\circ}$ and $1100^{\circ} \mathrm{C}$ as a function of the excitation wavelength. The correlation between the crystal field strength of $\mathrm{Eu}^{3+}$ sites and the ${ }^{5} \mathrm{D}_{0} \leftarrow{ }^{7} \mathrm{~F}_{0}$ band energy can be clearly observed. Specifically, the crystal-field strength $N_{v}\left(B_{2 q}\right)$ decreased with the increase of the excitation wavelength, indicating that high energy ${ }^{5} \mathrm{D}_{0} \leftarrow{ }^{7} \mathrm{~F}_{0}$ bands are linked to high-field-strength bonding sites and low energy ${ }^{5} \mathrm{D}_{0} \leftarrow{ }^{7} \mathrm{~F}_{0}$ bands are related to low-field-strength sites.

According to the excitation energy, two domains, which are designated as site I and site II, can be clearly observed in Fig. 5. For the higher energy domain (wavelength $<574 \mathrm{~nm}$ ), the crystal field strength is higher and changes a little with the variation of excitation wavelength; for the lower energy domain (wavelength $>574 \mathrm{~nm}$ ), the crystal field strength varies sharply with the excitation energy. It is reported in our previous paper that most of the $\mathrm{Eu}^{3+}$ sites perturbed by the presence of $\mathrm{Hf}$ are excited by lower energy. ${ }^{8}$ So the $\mathrm{Eu}^{3+}$ sites corresponding to high energy wing (site I) are associated with the sites unperturbed by Hf, while the sites excited by lower energy (site II) are related to $\mathrm{Eu}^{3+}$ sites perturbed by the presence of $\mathrm{Hf}$.

An important concept for understanding local $\mathrm{Eu}^{3+}$ structure in silicate glasses is the nonbridging oxygen (NBO) concentration in the material. ${ }^{26}$ NBOs are covalently bonded to one $\mathrm{Si}$ atom $\left(\mathrm{Si}-\mathrm{O}^{-}\right)$rather than the two $\mathrm{Si}$ atoms $(\mathrm{Si}-\mathrm{O}-\mathrm{Si})$ linked by bridging oxygens (BO). For the samples investigated in the present study, NBO can be formed through the incorporation of $\mathrm{HfO}_{2}$ in the glass matrix. $\mathrm{HfO}_{2}$ can act as glass modifier, depolymerizing the silicate matrix through the formation of NBO. $\mathrm{Eu}^{3+}$ sites highly influenced by the presence of hafnium are associated with a high local concentration of NBO and the other $\mathrm{Eu}^{3+}$ sites unperturbed are characterized by a low local concentration of NBO. Eu-O bonds are more covalent when the oxygens are nonbridging due to the increased partial charge and polarizability near NBO sites as compared with BO. Thus, Hf-perturbed $\mathrm{Eu}^{3+}$ sites (site II) exhibit a more covalent character compared with those of site I.

\section{Conclusions}

In summary, $\mathrm{Eu}^{3+}$-doped $\mathrm{SiO}_{2}-\mathrm{HfO}_{2}$ glasses were successfully synthesized using sol-gel method and the effect of thermal treatment on the properties of this kind of material was investigated. The splitting of emission band corresponding to ${ }^{5} \mathrm{D}_{0} \rightarrow{ }^{7} \mathrm{~F}_{2}$ transition of $\mathrm{Eu}^{3+}$ ions occurred for the samples sintered at temperatures higher than $1000^{\circ} \mathrm{C}$, which can be explained by the formation of crystals in these samples. Also, an obvious lengthening of the lifetime with increasing sintering temperature of the samples was observed. Analysis of FLN spectra using crystal field theory reveals the correlation between $\mathrm{Eu}^{3+}$ site crystal field strength and the ${ }^{5} \mathrm{D}_{0} \leftarrow{ }^{7} \mathrm{~F}_{0}$ band energy. Two kinds of $\mathrm{Eu}^{3+}$ site, one unperturbed by $\mathrm{Hf}$ and the other one perturbed by the presence of $\mathrm{Hf}$, are coexisting in the samples.

\section{Acknowledgments}

The authors acknowledge Angers Loire Metropole for a post-doctoral fellowship to Chaofeng Zhu. The authors also express their sincere thanks to Dr. Wenhua Bi (Université d'Angers) for XRD measurements and helpful discussions.

\section{References}

${ }^{1}$ J. K. Richard Weber, J. G. Abadie, T. S. Key, and K. Hiera, "Synthesis and Optical Properties of Rare-Earth-Aluminum Oxide Glasses," J. Am. Ceram. Soc. 85 [5] 1309-11 (2002).

${ }^{2}$ Y. H. Kim, U. C. Paek, and W. T. Han, "Absorption and Emission Properties of $\operatorname{Tm}[2]^{+}$Ions in Germanosilicate Glass Fibers," Opt. Express, 11 [21] 2672-8 (2003).

${ }^{3}$ W. A. Pisarski, T. Goryczka, and J. Pisarska, "Er-Doped Lead Borate Glasses and Transparent Glass Ceramics for Near-Infrared Luminescence and Up-Conversion Applications," J. Phys. Chem. B, 111 [10] 2427-30 (2007).

${ }^{4}$ S. Berneschi, G. Nunzi Conti, I. Banyasz, A. Watterich, N. Q. Khanh, M. Fried, and F. Paszti, "Ion Beam Irradiated Channel Waveguides in $\mathrm{Er}^{3+}$-Doped Tellurite Glass," Appl. Phys. Lett., 90, 121136-8 (2007).

${ }^{5}$ S. Bhandarkar, "Sol-Gel Processing for Optical Communication Technology," J. Am. Ceram. Soc., 87 [7] 1180-99 (2004).

${ }^{6}$ V. Sudarsan, S. Sivakumar, F. C. Veggel, and M. Raudsepp, "General and Convenient Method for Making Highly Luminescent Sol-Gel Derived Silica and Alumina Films by Using $\mathrm{LaF}_{3}$ Nanoparticles Doped with Lanthanide Ions $\left(\mathrm{Er}^{3+}\right.$, $\mathrm{Nd}^{3+}$, and $\mathrm{Ho}^{3+}$ )," Chem. Mater., 17 [18] 4736-42 (2005).

${ }^{7}$ C. Canevali, M. Mattoni, F. Morazzoni, R. Scotti, and M. Casu, "Stability of Luminescent Trivalent Cerium in Silica Host Glasses Modified by Boron and Phosphorus," J. Am. Chem. Soc., 127 [42] 14681-91 (2005).

${ }^{8}$ A. Monteil, M. EI-Jouad, G. Alombert-Goget, S. Chaussedent, N. Gaumer, A. Mahot, A. Chiasera, Y. Jestin, and M. Ferrari, "Relationship Between Structure and Optical Properties in Rare Earth-Doped Hafnium and Silicon Oxides: Modeling and Spectroscopic Measurements," J. Non-Cryst. Solids, 354 [42-44] 4719-22 (2008).

${ }^{9}$ J. M. Ruano, V. Benoit, J. S. Aitchison, and J. M. Cooper, "Flame Hydrolysis Deposition of Glass on Silicon for the Integration of Optical and Microfluidic Devices," Anal. Chem., 72 [5] 1093-7 (2000).

${ }^{10}$ G. Dantelle, M. Mortier, D. Vivien, and G. Patriarche, "Effect of $\mathrm{CeF}_{3}$ Addition on the Nucleation and Up-Conversion Luminescence in Transparent Oxyfluoride Glass-Ceramics," Chem. Mater., 17 [8] 2216-22 (2005).

${ }^{11}$ Y. Jestin, C. Armellini, A. Chiappini, A. Chiasera, M. Ferrari, C. Goyes, M. Montagna, and E. Moser, "Erbium Activated $\mathrm{HfO}_{2}$ Based Glass-Ceramics Waveguides for Photonics," J. Non-Cryst. Solids, 353 [5-7] 494-7 (2007).

${ }^{12}$ A. Peled, A. Chiasera, M. Nathan, M. Ferrari, and S. Ruschin, "Monolithic Rare-Earth Doped Sol-Gel Tapered Rib Waveguide Laser," Appl. Phys. Lett., 92, 221104-1, 3pp (2008).

${ }^{13}$ F. A. Sigoli, R. R. Goncalves, A. S. Camargo, L. A. O. Nunes, Y. Messaddeq, and S. J. L. Ribeiro, "Preparation and Characterization of Erbium and Ytterbium Co-Doped Sol-Gel $\mathrm{SiO}_{2}: \mathrm{HfO}_{2}$ Films for Planar Waveguides," Opt. Mater., 30 [4] 600-7 (2007).

${ }^{14}$ G. Alombert-Goget, N. Gaumer, J. Obriot, A. Rammal, S. Chaussedent, A. Monteil, H. Portales, A. Chiasera, and M. Ferrari, "Aluminum Effect on Photoluminescence Properties of Sol-Gel-Derived Eu ${ }^{3+}$-Activated Silicate Glasses," J. Non-Cryst. Solids, 351 [21-23] 1754-8 (2005).

${ }^{15}$ A. Monteil, S. Chaussedent, G. Alombert-Goget, N. Gaumer, J. Obriot, S. J L. Ribeiro, Y. Messaddeq, A. Chiasera, and M. Ferrari, "Clustering of Rare Earth in Glasses, Aluminum Effect: Experiments and Modeling," J. Non-Cryst. Solids, 348, 44-50 (2004).

${ }^{16} \mathrm{G}$. Lakshminarayana and J. R. Qiu, "Photoluminescence of $\mathrm{Eu}^{3+}, \mathrm{Tb}^{3+}$ and $\mathrm{Tm}^{3+}$-Doped Transparent $\mathrm{SiO}_{2}-\mathrm{Al}_{2} \mathrm{O}_{3}-\mathrm{LiF}-\mathrm{GdF}_{3}$ Glass Ceramics," J. Alloy. Compd., 476 [1-2] 720-7 (2009).

${ }^{17}$ Y. Dwivedi and S. B. Rai, "Optical Properties of $\mathrm{Eu}^{3+}$ in Oxyfluoroborate Glass and its Nanocrystalline Glass," Opt. Mater., 31 [1] $87-93$ (2008). 
${ }^{18}$ G. H. Lee, T. H. Kim, C. Yoon, and S. Kang, "Effect of Local Environment and $\mathrm{Sm}^{3+}$-Codoping on the Luminescence Properties in the $\mathrm{Eu}^{3+}$-Doped Potassium Tungstate Phosphor for White LEDS," J. Lumin., 128 [12] 1922-6 (2008).

${ }^{19}$ N. D. Afify, G. Dalba, C. Armellini, and Y. Jestin, "XRD and EXAFS Studies of $\mathrm{HfO}_{2}$ Crystallization in $\mathrm{SiO}_{2}-\mathrm{HfO}_{2}$ Films," Mat. Sci. Semicon. Proc., 9 [6] 1043-8 (2006).

${ }^{20}$ Y. G. Su, L. P. Li, and G. S. Li, "Synthesis and Optimum Luminescence of $\mathrm{CaWO}_{4}$-Based Red Phosphors with Codoping of $\mathrm{Eu}^{3+}$ and Na," Chem. Mater., 20 [19] 6060-7 (2008).

${ }^{21}$ D. Jain, V. Sudarsan, R. K. Vatsa, and C. G. S. Pillai, "Luminescence Studies on $\mathrm{Zn}-\mathrm{P}_{2} \mathrm{O}_{5}$ Glasses Doped with $\mathrm{Gd}_{2} \mathrm{O}_{3}$ :Eu Nanoparticles and $\mathrm{Eu}_{2} \mathrm{O}_{3}$," J. Lumin., 129 [5] 439-43 (2009).

${ }^{22}$ Y. A. Malinovskii and O. S. Bondareva, "Refined Crystal Structure of $\mathrm{Er}_{2} \mathrm{O}_{3}$," Soviet Phys. Crystallogr., 36 [6] 882-3 (1991).
${ }^{23}$ N. D. Afify, R. Grisenti, G. Dalba, C. Armellini, M. Ferrari, S. Larcheri, F. Rocca, and A. Kuzmin, "Short-Range Order Around $\mathrm{Er}^{3+}$ in Silica Waveguides Containing Aluminum, Titanium and Hafnium," Opt. Mater., 28 [6-7] 864-7 (2006).

${ }^{24}$ W. Y. Jia, H. M. Liu, S. P. Felofilov, R. Meltzer, and J. Jiao, "Spectroscopic Study of $\mathrm{Eu}^{3+}$-Doped and $\mathrm{Eu}^{3+}, \mathrm{Y}^{3+}$ Codoped $\mathrm{SiO}_{2}$ Sol-Gel Glasses," J. Alloy. Compd., 311 [1] 11-5 (2000).

${ }^{25}$ N. Ollier, G. Panczer, B. Champagnon, and G. Boulon, "Europium as a Luminescent Probe of an Aluminoborosilicate Nuclear Glass and its Weathering Gels," J. Lumin., 94-95, 197-201 (2001).

${ }^{26}$ M. J. Lochhead and K. L. Bray, "High-Pressure Fluorescence Line Narrowing of Eu(III)-Doped Sodium Disilicate Glass," Phys. Rev. B, 52 [22] 15763-75 (1995). 